\title{
Hard Skin Syndrome Parana Type
}

National Cancer Institute

\section{Source}

National Cancer Institute. Hard Skin Syndrome Parana Type. NCI Thesaurus. Code C126559.

A rare disorder characterized by rigid, thick skin that covers the entire body and affects movements. The movement of the chest and abdomen is severely restricted. Affected individuals develop respiratory insufficiency which may lead to death. 